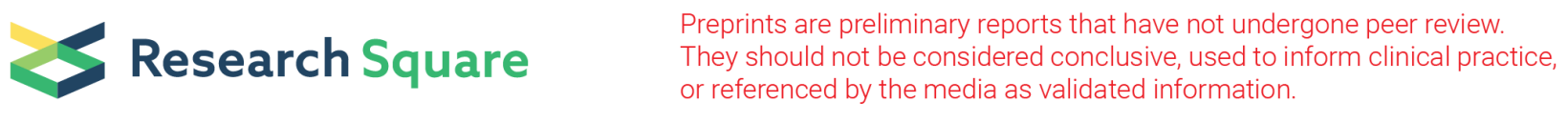

\title{
Prioritization of hydroelectric power plant earth dam safety procedures: a multicriteria approach
}

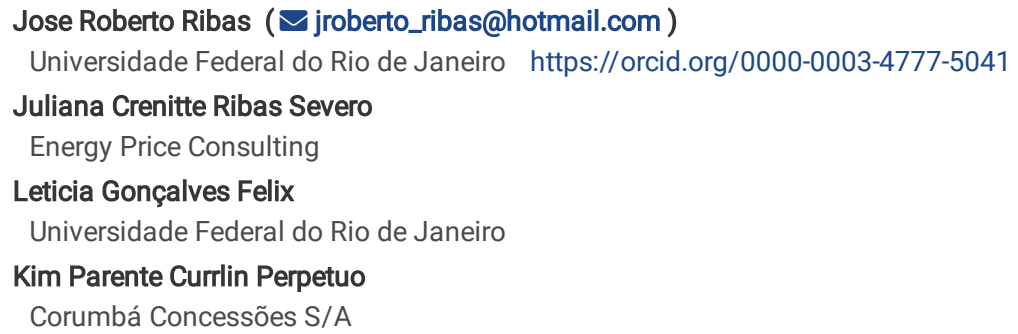

\section{Research Article}

Keywords: Safety procedures, hydroelectric power plant, dam vulnerability, monitoring, MCDA

Posted Date: April 21st, 2021

DOI: https://doi.org/10.21203/rs.3.rs-360591/v1

License: (c) (i) This work is licensed under a Creative Commons Attribution 4.0 International License. Read Full License 


\section{Abstract}

The number of procedures focused on dam safety is very large, mainly due to the rules established by different regulatory bodies, the guidelines that are part of the recommended best practices for engineering works, and the common sense and conservatism present in dam operation and maintenance because of the large socioeconomic and environmental impacts that any incident with a dam can cause. In practice, the vulnerability of a dam is inversely proportional to the improvement of safety procedures, such as monitoring and sensing, and the staff's capacity to interpret the information in timely fashion. Therefore, establishing priorities for these procedures is essential for the plant management to define the scheduling and detailing of inspections and monitoring, as well as training needs. The MCDA model described here was specified based on regulations and practical public domain guidelines. The subjective estimation of preferences was done by the staff of a hydroelectric plant located in central Brazil. It employed the Simos method combined with a procedure adopted to convert the scores to the format of paired comparisons. The weights for dam safety procedures were obtained using the fuzzy AHP method. The method allowed obtaining the classification of safety procedures according to their priorities, and thus provided the plant management with elements to better schedule monitoring and staff training.

\section{Introduction}

Vulnerability and reliability are antagonistic concept. The former is a more wide-ranging concept, with much broader implications. While reliability focuses on the possibility of maintaining the performance of infrastructure elements, vulnerability focuses on the potential for disrupting these elements or degrading them to a point where performance is diminished. Vulnerable does not necessarily mean unreliable, nor does unreliable necessarily mean vulnerable. Reliability is a probabilistic measure of elements in an infrastructure system and their ability not to fail or malfunction, given a series of established benchmarks or performance guidelines (Murray and Grubesic, 2007), while vulnerability is a fragility or defect in the design, operation and/or management, making the infrastructure subject to failure or stoppage when exposed to a hazard or threat (Zio, 2016).

Dams are key assets in terms of critical infrastructure (Murray A.T., Grubesic T.H. 2007). The extent and severity of a cascading effect depends on how tightly coupled and vulnerable the infrastructure systems are (Little, 2002). In event-driven risk models, the probability of occurrence of events or hazards of a certain level are inputs triggering the probability of poor performance or vulnerability, which results in the probability of a set of likely consequences. Depending on the adverse effect of the event on the facility's performance, the consequence can be dam failure (Baecher, 2016). The assessment of the physical vulnerability of elements at risk as part of the risk analysis is an essential aspect for the development of strategies and structural measures for risk reduction. Understanding, analyzing, and where possible quantifying physical vulnerability is a prerequisite for designing strategies and adopting tools for this reduction (PapathomaKöhle, 2016). A dam fails due to a severe event that can result from heavy rainfall, earthquakes, strong winds, snow and ice, volcanic action, landslides, tsunamis, and wildfires. All of these events can cause some degree of risk to dams and related infrastructure. To these natural hazards, one can add terrorist acts, design defects, excessively long service lives, aging materials, and unsatisfactory maintenance (Little, 2002). When any of these events occurs, the extent of the dam's vulnerability determines whether or not it remains intact. One or a combination of the following vulnerabilities may cause its failure: (a) inadequate design caused by the inability to predict extreme environmental events or insufficient site assessment; (b) design flaws; (c) faults or poor engineering practices and inadequate site supervision during construction and filling of the reservoir; and (d) deficient surveillance, monitoring, and maintenance (Donnelly \& Acharya, 2020). With respect to the last item, a significant probability of failure is due to human factors, including maintenance, inattention to regular testing, faulty communication during an emergency, or incorrect action at the moment before the occurrence. This involves both cognitive and physical responses that, depending on the event sequence, can have results ranging from minor loss to catastrophic failure (Baecher, 2016). Most failed dams either did not have any monitoring system or had a system that was out of order (ICOLD, 1995). The most usual safety indicators can be classified into three categories: mechanical effects such as deformation and displacement; hydraulic effects such as seepage and pore water pressure; and environmental effects such as high reservoir water levels, precipitation, and temperature (Santillán et al., 2013). Among these indicators, the monitoring of pore water pressure is essential to assure dam geotechnical stability because it detects the internal erosion and seepage problems (Pan \& Dias, 2016, Pagano et al., 2010), although the materials used in the internal structure of dams are arranged in zones to enhance the potential filtering capability to arrest piping if it starts (Koelewijn and Bridle 2017). The prudent maintenance practice uses all possible means to better understand dam performance, making inspection and monitoring methods more efficient. The actions developed and followed are: detailed monitoring and inspection through instrumentation, reading and interpretation of data; detailed emergency action plans, classified by type of hazard, containing step-by-step actions to be carried out by the people in charge; periodic reviews of the dam's status and evolutionary evaluation of indicators; detailed investigation of the indicators that reveal risk of failure; and preparation of a remediation plan and rehabilitation procedure (Adamo et al., 2017). Although the regulatory provisions on dam inspection and monitoring are consolidated (ICOLD, 2015), research that evaluates dam inspection and monitoring is rarely found in the academic literature (Lewin et al., 2003). The purpose of this article is to propose a multicriteria model to order the criteria adopted for the assessment of dam vulnerability in relation to operation, inspection, sensing and maintenance procedures.

In the case of risk assessment, safety and vulnerability of dams, several studies have been published. Andersen et al. (1999) proposed a multistep approach for the ranking of maintenance and repair actions and monitoring of embankment dams, where the most important action in terms of dam safety in the worst condition was preferred. Curt et al. (2008) adopted a possibility theory-based approach to validate different uncertain pieces of information based on sensory evaluations and global judgments. Curt and Talon (2013) suggested a method based on identification and assessment of criteria for the various sources of imperfection through visual observations, monitoring, calculation, and construction measurement. Then the ELECTRE TRI method was used to aggregate the values resulting from the assessment of the criteria. Vojteková and Vojtek (2020) applied a technique involving multicriteria decision analysis (MCDA) and a geographic information system (GIS) to identify and analyze landslide susceptibility at a local spatial scale. Larrauri and Lall (2020) obtained dam hazard ranking through AHP in a model focused primarily on identification of methods for the rapid quantification of the trigger probability of dam failure, and identification of the critical infrastructure that would be impacted if the dam fails. The fuzzy analytic hierarchy process (FAHP) has also been used in risk assessment (Arce et al. 2015, Govindan et al., 2015, Zou et al. 2013, Chan \& Wang 2013, Arikana et al. 2013, Li 2013, Avdi et al. 2013, Zeng \& Smith, 2007). 
Masoumi et al. (2018) adopted an integrated decision model based on FAHP-FTOPSIS methods to evaluate nine criteria and 42 alternative geotechnical instruments for monitoring and sensing of a clay core embankment dam. Jing et al. (2018) proposed a method for risk assessment of small reservoirs without monitoring equipment and verified the applicability and effectiveness of this method in two engineering cases. Yucesan and Kahraman (2019) adopted a Pythagorean fuzzy analytical hierarchy process (PFAHP) using linguistic expressions to calculate the weights of 20 hazards in the operation of hydroelectric power plants. Ribas and Pérez-Díaz (2019) used fuzzy approximate reasoning for dam safety risk assessment with FAHP to rank the indicators in a two-stage risk assessment process. Wijitkosum and Sriburi (2019) described four main factors influencing drought: climate, physical factors, soil and land utilization factors, each containing ten subcriteria to identify severity levels and specific issues.

\section{Materials And Methods}

\subsection{Fuzzy analytic hierarchy process}

The analytic hierarchy process (AHP) is a method that organizes a list of criteria in order of priority. The procedure uses pairwise comparisons, whose order of importance refers to an ordinal scale and depends on the subjective judgment of an expert. The expert is asked to estimate by how much one criterion dominates another with respect to a given attribute (Saaty, 2008).

AHP is a method that measures intangibles in relative terms, so when the expert tries to subjectively assess the relative importance between two criteria, he or she is conditioned to bounded rationality and heuristics (Hilbert, 2012). The first situation occurs because the brain's ability to process information is biologically limited, and the second occurs because the specialist tries to use shortcuts in the judgment to reduce the cognitive effort. This anomaly inherent in the subjective estimation procedure results in comparisons that incorporate biases and errors. To incorporate imprecision in the process of comparing criteria, a viable alternative is the fuzzification of scores using the FAHP. The technique takes the treatment of inaccuracy into account through a measure that represents the degree of fuzziness $(\delta)$. This metric is adopted to determine the a-cuts, boundaries of a fuzzy set characterized by a membership function, which are assigned to each pairwise comparison. This concept allows a given evaluation to have a clear numerical representation of something vague and imprecise, characteristic of the natural language used in the decision-making process (Klir and Yuan 1995).

The first solution for the FAHP method was proposed by Van Laarhoven and Pedrycz (1983), in which the fuzzified weights result from the normalized estimated values of a logarithmic regression. Buckley (1985) proposed a simpler approach, in which the criteria weights are equal to the relative means of the geometric means calculated along the columns of the fuzzy pairwise comparison matrix. Mikhailov (2000, 2002, 2003) proposed a solution of a linear programming problem which maximizes the consistency index or degree of satisfaction restricted to a set of inequalities based on the a-cuts and a certain degree of tolerance. The FAHP solution proposed by Chang (1996) is a synthesizing method whose algorithm resolves hierarchy problems associated with fuzzy logic (Zhua et al., 1999), which has proven to be practical and transparent (Kahraman et al., 2003). However, the method has some practical problems. One occurs whenever zero is used as divisor or data are out of range (Zhu, et al., 1999). Such weakness is solved by altering the fuzzified values to 1, 9 or 1/9, depending on the case. In addition, the extent analysis method may assign a zero weight to one or more dominated criteria, causing the criterion/criteria to be disregarded in the decision process (Wang et al., 2008). This is solved by assigning high values to $\delta$ (Ribas et al., 2019). Finally, it is difficult to meet the consistency requirement in pairwise comparison, which gets worse when the number of criteria is large. Ribas and da Silva (2015) proposed the adoption of the Simos method (Figueira \& Roy, 2002; Pictet \& Bollinger, 2005), which significantly reduces the risk of inconsistency during the comparison process and also decreases the effort of subjectively assigning the scores (Li et al., 2013).

\subsection{Specification Phase}

The flowchart of Figure 1 depicts the progress in three phases of the FAHP method: specification, scoring and weighting. The surveillance, instrumentation, monitoring, and data acquisition of the dam involve periodic readings and systematic analysis of the installed geotechnical instrumentation, whose which degree of detail and frequency of inspections depend on the age, size and location of the dam. In addition, the applicable regulations determine the elaboration of contingency plans for different hazard scenarios, such as operational actions in emergency situations, instructions, communication, and evacuation routes for those affected downstream. Each criterion is detailed for structural elements, types of measurement instruments, specific procedures for each hazard scenario and maintenance routines, as appropriate, and the subcriteria are analyzed and compared with each other to avoid redundancies. Acronyms are assigned to the criteria and subcriteria to facilitate identification in the FAHP model.

\subsection{Scoring Phase}

The expert is provided with the letters identified with the criterion acronyms and several blank letters, following the Simos method (Figueira \& Roy, 2002; Pictet \& Bollinger, 2005). The letters containing the criterion identifications are lined up by the specialist in decreasing order of importance. When two criteria are judged to be of equal importance, the cards are placed side by side. Then the expert is asked to insert one, two or three blank cards between the identified cards, for comparisons as being "a little more important", "more important" or "much more important", respectively. Each criterion card has a score corresponding to its classification in decreasing order. The division of this score by the sum of the scores of all criteria results in a normalized score. Although the blank card occupies a position, no score is assigned to it since it is not a criterion. Instead of performing the normalization on the 100 bases, as proposed by the Simos method, or using the perception of difference between the two criteria for the extremes of preference, according to the revised Simos method, we adopted the base scale eight plus one. The result for the numerator or denominator, depending on the direction of preference, must be rounded to the nearest integer so the criteria scores can be converted to the equivalent Saaty scale. The advantage of this approach is that the resulting matrix is transitive (Ribas \& da Silva, 2015).

\subsection{Weighting Phase}


The degree of fuzziness (d) is set subjectively for the expert based on the extent of his/her expertise on the topic of analysis (Espino et al., 2014; Keprate \& Ratnayake, 2016). The purpose of $\delta$ is to compensate for the lack of precision of the specialist when making comparisons between the criteria by establishing an a-cut for a triangular membership function (TMF). The $\delta$ value is 1.0 when the expert has participated in similar projects and has demonstrated high involvement during the elicitation phase. The value of $\delta$ is 2.0 when either one of these two requirements is met, and is equal to 3.0 otherwise. A fuzzy number $M_{i j}$ described by a TMF assumes values in the interval [1/9.9] and is represented by the lower $\left(l_{i j}=m_{i j-d}\right)$, modal $\left(m_{i j}\right)$, and upper values $\left(u_{i j}=m_{i j}+d\right)$. The fuzzy synthetic extent $\left(S_{i}\right)$ for each $M_{i j}$ is determined, noting that each $M_{i j}$ is a TMF, so that $S_{i}$ is a triplet containing lower, modal, and upper values. When comparing two convex fuzzy numbers $S_{1}$ and $S_{2}$, the degree of possibility must be a value between 0 and 1 , determined through the min operator. The weight vector is obtained by normalizing the degree of possibility vector. Then, the normalized weights calculated for the criteria and the subcriteria are presented to the expert, who will judge whether the results are consistent with his/her expectations. If not, the scoring phase should be reevaluated.

\section{Case Study}

The Corumbá IV hydropower plant is located on the upper reach of the Corumbá River, at the geographical coordinates $16^{\circ} 19^{\prime} 22^{\prime} S$ and $48^{\circ} 11^{\prime} 15^{\prime \prime} W$, in Goiás state, Midwest Brazil (Figure 2). The Corumbá River is a tributary on the right bank of the Paranaíba River, and the Corumba IV reservoir is part of the reservoir system of the Paraná River's hydrographic basin. The reservoir has approximately $173 \mathrm{~km}^{2}$ of flooded area, a total maximum volume of about $3.7 \times 109 \mathrm{~m}$ (3.7 trillion liters) and a useful volume of $0.8 \times 109 \mathrm{~m}^{3}$ ( 800 billion liters). The filling of the reservoir began at the start of 2005 and the first generator went into operation about 11 months later. Its predominant shape is elongated, without excessive arms with relatively large depth. Its average depth is about $21 \mathrm{~m}$. The dam was built on the Corumbá riverbed, whose soil is composed of earth and sand, taking advantage of the construction materials that existed in the vicinity of the project. The completed dam is $10 \mathrm{~m}$ wide at the crest, $1,290 \mathrm{~m}$ long and has maximum height of $76 \mathrm{~m}$ in the stretch of the river channel. The dam core was built of clay soil, being impermeable and protected by other soils and externally by altered rock soils, which are more resistant. The powerhouse was built next to the left abutment of the dam and dimensioned to contain two sets of hydro generators and their auxiliary equipment. The total installed power is 127 $\mathrm{MW}$, divided into two generator sets of $63.5 \mathrm{MW}$ each. The energy generated by this project serves up to two million people per month, guaranteeing energy for the Federal District and surrounding region. The turbines are of the vertical axis Francis type, with armored spiral box and elbow suction tube, suitable for direct drive of three-phase alternating current generators. The spillway, on a free runway threshold, was designed for a load of two meters and has a capacity of $1,550 \mathrm{~m}^{3}$ per second, with a total length of $425 \mathrm{~m}$. It is a surface spillway with a dissipation basin. The water empties into a concrete structure, with free edge, that is, without gates, descending through an elongated "S" shaped structure that launches the water, called ski jump. The adduction circuit consists of a tower water intake, with seven openings protected by grids, through which water is captured and taken to the intake well, which was excavated in rock and covered with reinforced concrete. After descending through the intake well, the water reaches the adduction tunnel with a length of $394 \mathrm{~m}$, also excavated in rock and covered in reinforced concrete, the same tunnel that was used to divert the river during the construction phase. The final stretch of the tunnel, close to the powerhouse, metallic armor in addition to the concrete lining.

\section{Results And Discussion}

\subsection{Specification phase}

The vulnerability of a plant must be mitigated by means of methods, processes, instruments, and practices that are ideally able to predict and face situations of imminent danger. These elements were identified and classified according to the scope of use based on Brazilian dam safety legislation (Brasil, 2010), the technical guidelines of good engineering practices recommended for public and private generation concessionaires (Eletrobras, 2003) and the general guidelines for companies, aiming to ensure adequate safety conditions for dams, from construction to decommissioning (ANA, 2016). Nine elements identified within their respective scopes were used as criteria in the MCDA model. The subdivision of the subcriteria depends on the documents, processes, practices, or instruments as they were classified in the criteria.

Documentation (DOC): These records must meet dam safety criteria from preliminary and feasibility studies to the final project as constructed. In this item, we analyzed the available as-built designs, construction and commissioning documentation, project description and specifications, hydrological studies, geological and geotechnical studies, seismological studies, foundation studies, spillway design and water intake design. The subcriteria are: Preconstruction engineering and design (DOC.ENG); Hydrology investigations (DOC.HYD); Geotechnical investigations (DOC.GEO); Subsurface explorations and foundation investigations (DOC.FOU); Service spillway design (DOC.SPI); and Water intake design (DOC.WIN).

Inspections (INS): Dam safety inspections are divided into regular and special inspections, the first being carried out periodically, with frequency determined according to the risk category and potential damage, aiming at assessing and detecting the existence of anomalies. Regarding the regular safety inspection, the situation and level of danger related to regular inspections evaluates the upstream slope, downstream slope, right and left abutments, crest, spillway, water intake, reservoir, instrumentation, ducts and shielding, turbines, alternators, substation, and powerhouse. Regarding the special safety inspection, it will be prepared as instructed by a multidisciplinary team of specialists, depending on the risk category and the potential damage associated with the dam, in the construction, operation and deactivation, and must consider changes in conditions upstream and downstream of the dam. The subcriteria are: Riprap (INS.RIP); Downstream slope and toes (INS.DSL); Abutments (INS.ABU); Dam core (INS.COR); Service spillway (INS.SPI); Water intake (INS.WIN); Water physical-chemical properties (INS.WAT); Foundations (INS.FOU); and Surveillance and monitoring system (INS.MON).

Operation (OPE): It describes the procedures for the operation of the water intake, spillway, and sluice way, to allow satisfactory operation of the dam, in addition to keeping it in safe conditions and monitoring its behavior to detect any anomalies in a timely manner. In this part, the existence of procedures to be adopted in the operation of the reservoir is verified. The subcriteria are: Reservoir levels, affluent and effluent water flows (OPE.RES); Service spillway operating records (OPE.SPI); Detailed information concerning seepage control (OPE.SEC); Bottom outlet operating records (OPE.BOT); Water intake operating records (OPE.WIN); Reservoir water quality management (OPE.QUA); Operating procedure for extreme flood events (OPE.EXT); Operating instruction in the event of general flood gate failure (OPE.GAT); and Operating procedure in the event of loss of communication (OPE.COM). 
Maintenance (MAN): Maintaining structures and equipment in good condition is intended to ensure that the dam is kept in fully operational and safe condition. For this purpose, the equipment must be inspected and checked at regular intervals, as part of a maintenance program appropriate to the type of equipment, age, and intensity of use. Maintenance records of current actions involving the bus, spillway, instruments, and gates are checked. The subcriteria are: Updated maintenance logbook (MAN.LOG); Drainage system maintenance procedures (MAN.DRA); Spillway gates and chute maintenance procedures (MAN.SPI); Safety instrument maintenance procedures (MAN.ITM); Water intake maintenance procedures (MAN.WIN); and Reduction of the erosive process and siltation (MAN.ERO).

Monitoring and Instrumentation (MON): It includes the instrumentation of the body of the dam, the spillway structures, and the foundations. This criterion investigates the monitoring of the following factors (some related to instrumentation): neutral pressures at the landfill, landfill settlements, surface displacements, and seepage, among others. The dam instrumentation design must be elaborated from the feasibility study and basic design phases of the hydroelectric plant. It should contain the location of the instrumentation, along with the type and quantity of devices to be used. Instrumentation is an objective tool to monitor dams, being of fundamental importance in the safety procedures adopted. The most common instruments in earth dams and their respective functions are: topographic frame of reference for monitoring vertical and horizontal displacements; settlement sensors for measuring total and differential settlements and movement of materials; inclinometers for measuring displacements inside embankment dams or foundations; piezometers for measuring water pressures inside the dam body or at the foundation; total pressure cells in the landfill, to measure the total pressure in the landfill; flow meters for measuring the piping through the body of the dam and its foundation; water level gauge; and weather stations for measuring reservoir air and water temperatures and precipitation. The number of auscultation instruments to be installed in a dam depends on its height and length, geological formation of the soil and the materials used in the body of the dam. The frequency of readings should be adjusted depending on the occurrence of critical geotechnical or geological conditions, changes in construction procedures, rapid rises or falls of the reservoir level, and severe natural phenomena. The subcriteria are: Instrument installation and maintenance reports (MON.ITM); Routine visual and in situ inspections (MON.SIT); Geotechnical limits established for all inspection instruments (MON.GEO); Inspection of the maximum dam cross-section (MON.CRO); Inspection of sections with geological anomalies (MON.ANO); and Monitoring instrumentation calibration (MON.CAL).

Regular Revision and Updating (REV): The Brazilian Dam Safety Act (Brazil, 2010) states that, based on the dam risk classification, a regular dam safety review must be carried out to verify the general state of the dam, considering the current state of the art for the design criteria, the updating of the hydrological data and changes in conditions upstream and downstream. Thus, an extensive review of the technical documentation is carried out, comprising hydrological, geological, geotechnical, and seismological studies. The electric energy regulator audits the records related to the performance of the foundation, reservoir, spillway structure, earthen dam, operation and maintenance procedures, instrumentation, and monitoring. The outcome of the audit is the reassessment of the risk category and the associated potential damage. This criterion assesses whether the information available is sufficient to meet the requirements established by the auditors. The subcriteria are: Hydrology investigations (REV.HYD); Geotechnical investigations (REV.GEO); Foundation investigations (REV.FOU); Probable maximum flood (REV.MAX); Operation and maintenance plan (REV.OPM); and Monitoring instrument installation (REV.MON).

Emergency (EME): This criterion is based on the principle that the priority will be to save human lives. It must have an organized command line for emergency situations, with agile and standardized alert and communication procedures and a plan to resume operational capacity once the hazard has been controlled. The procedures must be specific to an external threat (invasion for example); fire; dam damage; inundation and leakage of chemical waste. Each threat must be determined according to the sequence of steps for device startups and shutdowns and plant evacuation. The subcriteria are: Disaster committee (EME.DIS); Emergency communication (EME.COM); Assignment of responsibilities (EME.REP); Mass care (EME.MAS); Animal care (EME.ANI); and Recovery (EME.REC).

Evacuation (EVA): The population affected by the dam must be identified to enable implementing an instruction plan and escape routes, aiming to minimize the damage and risks that may occur in a hypothetical breach. Therefore, in this criterion, a survey is performed to detect the existence or absence of programs for training the population and determining the escape routes: Instruction Plan, Escape Routes and Meeting Points, Self-Rescue Zone. The subcriteria are: Jurisdiction (EVA.JUR); Administration and logistics (EVA.ADM); Flash flood alarms (EVA.ALA); Escape routes and emergency exits (EVA.ROU); Mass care facilities (EVA.MAS); and Supplies of food, water, sanitation materials, clothing, bedding and first aid items (EVA.SUP).

Preparedness (PRE): Hydroelectric plant personnel must be trained and have equipment compatible with the type and severity of likely emergencies. This criterion ascertains the ability to perceive a situation of imminent risk and respond quickly, following pre-established procedures. The subcriteria are: Emergency staff (PRE.STA); Instrumentation repair training program (PRE.IRT); Power plant operational training courses (PRE.OPE); Power plant maintenance training courses (PRE.MAN); Visual and in situ monitoring training courses (PRE.SIT); Instrumentation reading and interpretation training courses (PRE.IRI); Regular revision and follow-up (PRE.REV); Emergency communication and action training exercises (PRE.EME); and Evacuation training exercises (PRE.EVA).

\subsection{Scoring and weighting phases}

To illustrate the scoring phase, we demonstrate the steps that were followed with the general manager (GM). Nine letters containing the identification of the criteria and several blank letters were handed to the interviewee. He was asked to rank the cards serially in order of importance, with two or more cards in parallel meaning a tie for that position. The interviewee thought that the order of importance was headed by INS and MON, second MAN, third REV and DOC, fourth OPE, and fifth PRE, EVA and EME. The degrees of importance between criteria were all judged to be "a little more important". Table 1 shows the steps of the Simos method used to obtain the criterion weights from the initial ordering, which are the criterion ranking, the number of criteria of each position, the position order, the average position, and the weights resulting from the average position divided by the sum of positions. The same table shows the scores according to the Saaty scale converted from the weights obtained by the Simos method (Ribas \& Silva, 2015). In this case, a change was made to the values for base 8 plus 1 for subsequent inversion.

Table 1. Criterion ranking, Simos weights and Saaty scores. 


\begin{tabular}{|c|c|c|c|c|c|c|}
\hline \multirow{2}{*}{ Rank } & \multicolumn{4}{|c|}{ Simos Weights } & \multicolumn{3}{c|}{ Saaty Scale } \\
\cline { 2 - 7 } \cline { 5 - 7 } & \#Criteria & Position & Average & Weights & Eight Base & Scores \\
\hline INS, MON & 2 & 1,2 & 1.5 & 2 & 1.92 & 8 \\
white & - & - & - & - & - & - \\
MAN & 1 & 4 & 4 & 6 & 3.46 & 7 \\
white & - & - & - & - & - & - \\
REV, DOC & 2 & 6,7 & 6.5 & 10 & 5 & 5 \\
white & - & - & - & - & - & - \\
OPE & 1 & 9 & 9 & 14 & 6.54 & 3 \\
white & - & - & - & - & - & - \\
PRE, EVA, EME & 3 & $11,12,13$ & 12 & 18 & 8.38 & 2 \\
\hline
\end{tabular}

Table 2 shows the matrix of paired comparisons, which together with fuzzification degree equal to 3.0 constitute the input data of the fuzzy AHP method. The resulting weights for the criteria can be seen in the last column. The degree of fuzzification of this magnitude suggests that the experts' inaccuracy in estimating preference levels is relatively high. For example, the degree of preference of INS in relation to MAN is obtained by subtracting the two scores plus one, so the difference between the two scores (8-7) +1 equals 2 , representing slight preference for INS.

Table 2. Paired comparisons matrix and the estimated criterion weights.

\begin{tabular}{|cccccccccc|c|}
\hline & INS & MON & MAN & VER & DOC & OPE & PRE & EVA & EME & WEIGHTS \\
INS & 2 & 1 & 2 & 4 & 4 & 6 & 7 & 7 & 7 & 0.2274 \\
MON & 1 & 1 & 2 & 4 & 4 & 6 & 7 & 7 & 7 & 0.2254 \\
MAN & $1 / 2$ & $1 / 2$ & 1 & 3 & 3 & 5 & 6 & 6 & 6 & 0.2072 \\
REV & $1 / 4$ & $1 / 4$ & $1 / 3$ & 1 & 1 & 3 & 4 & 4 & 4 & 0.1700 \\
DOC & $1 / 4$ & $1 / 4$ & $1 / 3$ & 1 & 1 & 3 & 4 & 4 & 4 & 0.1700 \\
OPE & $1 / 6$ & $1 / 6$ & $1 / 5$ & $1 / 3$ & $1 / 3$ & 1 & 2 & 2 & 2 & 0.1175 \\
PRE & $1 / 7$ & $1 / 7$ & $1 / 6$ & $1 / 4$ & $1 / 4$ & $1 / 2$ & 1 & 1 & 1 & 0.0806 \\
EVA & $1 / 7$ & $1 / 7$ & $1 / 6$ & $1 / 4$ & $1 / 4$ & $1 / 2$ & 1 & 1 & 1 & 0.0806 \\
EME & $1 / 7$ & $1 / 7$ & $1 / 6$ & $1 / 4$ & $1 / 4$ & $1 / 2$ & 1 & 1 & 1 & 0.0806 \\
\hline
\end{tabular}

The Simos method was also used in the comparisons between the subcriteria for each of the nine criteria. We adopted a variant of the AHP method to determine the degrees of importance, that is, instead of making cross-comparisons, we compared each set of subcriteria within each criterion. The reasons is that we were not establishing a ranking of the alternatives, but rather trying to classify the safety methods and procedures necessary to ensure the reduction of the dam's vulnerability to the risk of incidents of any nature. To exemplify, we now demonstrate the results obtained in the interview with the PM for estimation of the weights of the safety procedures adopted in the scope of maintenance. As can be seen in Table 3, the PM estimated that, in terms of dam safety, Updated maintenance logbook (MAN.LOG); Drainage system maintenance procedures (MAN.DRA) and Reduction of the erosive process and siltation (MAN.ERO) are more important than Spillway gates and chute maintenance procedures (MAN.SPI); Security instruments maintenance procedures (MAN.ITM); and Water intake maintenance procedures (MAN.WIN). The last column shows the scores according to the Saaty scale converted from the weights obtained by the Simos method.

Table 4 is assembled in the same way as Table 2 . The last column shows that the weights for three of the subcriteria are identical and much higher than the weights of the other three. This result stems from the PM's preferences, as shown in Table 3.

Table 3. Subcriterion ranking, Simos weights and Saaty scores.

\begin{tabular}{|c|c|c|c|c|c|c|c|c|}
\hline \multirow{2}{*}{ Rank } & \multicolumn{9}{|c|}{ Simos Weights } & \multicolumn{3}{c|}{ Saaty Scale } \\
\cline { 3 - 8 } & \#Criteria & Position & Average & Relative & Control & Weights & Eight Base & Scores \\
MAN.LOG, MAN.DRA, MAN.ERO & 3 & $1,2,3$ & 2 & 7 & 21 & 7 & 3.0 & 7 \\
White & - & - & - & - & - & - & - & - \\
White & - & - & - & - & - & - & - & - \\
MAN.ITM, MAN.SPI, & 3 & $6,7,8$ & 7 & 26 & 78 & 26 & 8.0 & 2 \\
MAN.WIN & & & & & & & & \\
\hline
\end{tabular}

Table 4. Paired comparison matrix and the estimated subcriterion weights.

\begin{tabular}{|cccccccc|c|}
\hline & MAN.LOG & MAN.DRA & MAN.ERO & MAN.ITM & MAN.SPI & MAN.WIN & WEIGHTS \\
MAN.LOG & 1 & 1 & 1 & 6 & 6 & 6 & 0.2582 \\
MAN.DRA & 1 & 1 & 1 & 6 & 6 & 6 & 0.2538 \\
MAN.ERO & 1 & 1 & 1 & 6 & 6 & 6 & 0.2538 \\
MAN.ITM & $1 / 6$ & $1 / 6$ & $1 / 6$ & 1 & 1 & 1 & 0.1171 \\
MAN.SPI & $1 / 6$ & $1 / 6$ & $1 / 6$ & 1 & 1 & 1 & 0.1171 \\
MAN.WIN & $1 / 6$ & $1 / 6$ & $1 / 6$ & 1 & 1 & 1 & 0.1171 \\
\hline
\end{tabular}

The procedure exemplified for the MAN criterion was performed for the others. Then, the weights obtained for the criteria according to Table 2 were multiplied by the weights obtained for the subcriteria and by 100 . The results of the PM's ranking can be seen in Table 5 , in which the degrees of importance for the methods and procedures related to mitigation of the dam's vulnerability are in the range of 1.06 to 5.35, with an average of 1.42 and a standard deviation of 2.59.

The degrees of Table 5 according to the PM as well as other experts were classified in four classes, where C.1 denotes the "essential" methods and procedures; C.2 those of "high importance"; C.3 those of "medium importance"; and C4 the "least important". The 
classifications were obtained through the quartiles calculated from the degrees of importance of each expert. The cutoff values according to the PM, for example, are 1.39, 2.36 and 3.73, for C.4, C.3, C.2 and C.1, respectively.

Table 5. Degrees of importance of dam safety methods and procedures.

\begin{tabular}{|cc|cc|cc|cc|cc|}
\hline INS.FOU & 5.27 & OPE.SEC & 2.52 & PRE.OPE & 1.95 & DOC.SPI & 3.83 & EVA.JUR & 2.38 \\
INS.RIP & 4.37 & OPE.COM & 2.52 & PRE.MAN & 1.95 & DOC.WIN & 3.83 & EVA.ALA & 1.80 \\
INS.DSL & 4.37 & OPE.RES & 2.52 & PRE.EME & 1.39 & DOC.ENG & 3.63 & EVA.ROU & 1.80 \\
INS.ABU & 4.37 & OPE.GAT & 2.09 & PRE.STA & 1.39 & DOC.FOU & 2.94 & EVA.MAS & 1.04 \\
INS.COR & 4.37 & OPE.EXT & 2.09 & PRE.EVA & 1.39 & DOC.GEO & 2.77 & EVA.SUP & 1.04 \\
INS.WIN & 3.17 & OPE.SPI & 1.31 & PRE.IRT & 1.39 & DOC.HYD & 1.31 & EVA.ADM & 1.04 \\
INS.SPI & 3.17 & OPE.BOT & 1.31 & PRE.IRI & 1.39 & REV.OPM & 4.40 & MON.CRO & 5.75 \\
INS.WAT & 1.39 & OPE.WIN & 1.31 & PRE.SIT & 1.39 & REV.MON & 4.04 & MON.SIT & 5.75 \\
INS.MON & 1.39 & OPE.QUA & 0.39 & PRE.REV & 0.39 & REV.GEO & 2.86 & MON.ANO & 4.34 \\
EME.REC & 2.06 & EME.DIS & 1.55 & MAN.LOG & 5.35 & REV.HYD & 2.86 & MON.GEO & 4.34 \\
EME.COM & 2.06 & EME.MAS & 0.85 & MAN.DRA & 5.26 & REV.FOU & 2.86 & MON.ITM & 2.36 \\
EME.REP & 1.55 & EME.ANI & 0.85 & MAN.ERO & 5.26 & REV.MAX & 1.15 & MON.CAL & 2.36 \\
MAN.SPI & 2.43 & MAN.WIN & 2.43 & MAN.ITM & 2.43 & & & & \\
\hline
\end{tabular}

To obtain a single aggregated classification, it is essential to reject all hypotheses of significant difference between the estimates among the five experts: general manager (GM), electric engineer (EE), mechanical engineer (ME), civil engineer (CE), and consultant (CO). For this purpose, Spearman correlation coefficients are calculated by comparing the results between pairs of specialists. As can be seen in Table 6, the estimates of the subcriterion positions among them have no significant differences, with p-values close to zero in all cases. Such statistics confirm the inexistence of significant differences among the experts, allowing us to use the aggregated values, summarizing them in a single estimate for the entire group.

Table 6. Pairwise Spearman coefficients between the degrees of importance of the experts.

\begin{tabular}{|cccccccccccc|}
\hline & GMxEE & GMxME & GMxCE & GMxCO & EExME & EExCE & EExCO & MExCE & MExCO & CExCO \\
Statistics & 0.9981 & 0.9977 & 0.9984 & 0.9972 & 0.9991 & 0.9982 & 0.9986 & 0.9988 & 0.9987 & 0.9986 \\
p-value & 0.0000 & 0.0000 & 0.0000 & 0.0000 & 0.0000 & 0.0000 & 0.0000 & 0.0000 & 0.0000 & 0.0000 \\
\hline
\end{tabular}

Table 7 shows the importance classes estimated by the five specialists and the aggregate estimate. Most of the subcriteria deemed essential are related to the inspection procedures of critical parts of the dam and the reliability of such instruments. Internal erosion with increased pore pressure and saturation of the dam and foundation causes loss of resistance, which explains the relevance of regular inspections of the riprap (INS.RIP); downstream slope and toes (INS.DSL); abutments (INS.ABU) and dam core (INS.COR); monitoring instrument installation and maintenance reports (MON.ITM); routine of visual and in situ inspections (MON.SIT); the geotechnical limits established for all inspection instruments (MON.GEO) and the safety instrument maintenance procedures (MAN.ITM). Some of these subcriteria are related to operating instructions regarding the occurrence of extreme and unexpected events: procedures in the case of extreme flood events (OPE.EXT); the operating instruction in the event of loss of communication (OPE.COM) and in the case of general flood gate failure (OPE.GAT). The remaining essential subcriteria have to do with training, preventive O\&M and geotechnical documentation: the updated maintenance logbook (MAN.LOG); the spillway gates and chute maintenance procedures (MAN.SPI); the power plant operational training courses (PRE.OPE) and maintenance training courses (PRE.MAN); the documentation of geotechnical investigations (DOC.GEO); and the operating procedures for the affluent and effluent water flows (OPE.RES). Therefore, when the experts expressed their preferences regarding the methods and procedures to mitigate the dam's vulnerability, they emphasized the actions of inspecting parts of the dam and in reacting to extreme and unexpected events.

Table 7. Pairwise Spearman coefficients between the degrees of importance of the experts.

\begin{tabular}{|c|c|c|c|c|c|c|c|c|c|c|c|c|c|c|c|c|c|c|c|c|}
\hline & $\mathrm{M}$ & EE & ME & CE & $\mathrm{CO}$ & IVE & & GM & EE & ME & CE & $\mathrm{CO}$ & AVF & & GM & EE & $\mathrm{ME}$ & CE & $\mathrm{CO}$ & AVE \\
\hline & C.1 & C. 1 & C. 1 & C.1 & C.1 & C.1 & OPE.RES & C. 2 & C. 1 & C. 1 & C. 1 & C. 1 & C. 1 & PRE.OPE & С. 3 & C. 2 & C.1 & C. 1 & C. 1 & .1 \\
\hline & & C. 1 & .1 & C. 1 & C. 1 & 1 & & 2 & C. 1 & C.1 & C. 1 & C. 1 & .1 & & & C. 2 & C. 1 & C.1 & C. 1 & .1 \\
\hline & & C. 1 & .2 & .1 & C. 1 & & & C. 2 & C. 1 & C. 1 & C. 1 & C. 1 & .1 & & & C. 3 & C. 1 & C. 1 & C. 1 & 2 \\
\hline & & C. 1 & .2 & C. 1 & C. 1 & & & C. 3 & C. 1 & C. 1 & C.1 & C.1 & C. 1 & & & C. 3 & C. 1 & C. 1 & C. 1 & C. 2 \\
\hline & & C. 2 & 2 & C. 2 & C. 2 & & & & C. 2 & C. 2 & C.2 & C. 2 & C. 2 & & & C. 3 & C. 1 & C. 1 & C. 2 & .2 \\
\hline & 2 & C. 2 & C. 3 & C. 2 & C. 3 & & $\mathrm{OPI}$ & C. 4 & C. 2 & C. 2 & C. 2 & C. 2 & C. 2 & PRE & C. 3 & C. 3 & C. 2 & C. 2 & C. 2 & .2 \\
\hline & & C. 2 & .3 & C. 2 & C. 3 & & & C. 4 & C. 2 & C. 3 & C. 2 & C. 2 & C. 3 & JA & C. 3 & C. 3 & C. 2 & C. 3 & C. 2 & C. 3 \\
\hline & & 3 & .4 & .3 & .3 & & & & C. 3 & & C. 3 & C. 2 & & & & C. 4 & C. 2 & C.3 & C. 3 & .3 \\
\hline & 3 & C. 4 & C. 4 & C. 3 & C. 4 & C. 4 & $\mathrm{OPE}$ & C. 4 & C. 4 & C. 4 & C. 3 & C. 4 & C. 4 & PRE & C. 4 & C. 4 & C. 4 & C.3 & C. 4 & C. 4 \\
\hline & 1 & C. 1 & C. 2 & C. 1 & C. 1 & C. 1 & EMI & C. 3 & C. 1 & C. 2 & C. 4 & C. 2 & C. 2 & $\Gamma \mathrm{M}$ & C. 1 & C. 2 & C. 1 & C.1 & C. 2 & C. 1 \\
\hline & & C. 1 & .2 & C. 1 & C. 1 & & & 3 & C. 1 & C. 2 & C.4 & C. 2 & & & .1 & C. 2 & C. 1 & C.1 & C. 2 & .1 \\
\hline & 1 & C. 1 & C. 2 & C. 1 & C. 1 & $C_{1}$ & & C. 3 & C. 2 & C. 3 & C. 4 & C. 3 & C & & 1 & C. 2 & C. 2 & C. 1 & C. 2 & .1 \\
\hline & C. 1 & C. 2 & C. 3 & C. 2 & C. 1 & C. 2 & EMF & C. 3 & C. 2 & C. 3 & C. 4 & C. 3 & C. 3 & MA & C. 2 & C. 2 & C. 2 & C. 3 & C. 3 & C. 2 \\
\hline & 2 & C. 3 & C. 3 & C. 2 & C. 3 & .3 & EP & C. 4 & C. 3 & C. 3 & C. 4 & C. 3 & C. 4 & VIN & 2 & C. 3 & C. 3 & С.3 & C. 3 & C.3 \\
\hline & & C. 4 & C. 3 & C. 2 & C. 3 & 0.5 & & C. 4 & C. 4 & C. 4 & C. 4 & C. 4 & & & C. 2 & C. 4 & C. 4 & C. 3 & C. 4 & C. 4 \\
\hline & C.1 & C. 1 & C. 1 & C. 2 & C. 3 & C. 1 & EVA & C. 2 & C. 3 & C. 3 & C. 4 & C. 2 & C. 3 & & C. 1 & C. 4 & C. 4 & C. 2 & C. 3 & C. 3 \\
\hline & 1 & C. 1 & C. 1 & C. 2 & C. 4 & & & .3 & C. 3 & C & C. 4 & C. 2 & 3 & $\mathrm{ON}$ & 1 & C. 4 & C. 4 & C. 2 & C. 4 & C. 3 \\
\hline & C. 2 & C. 1 & C. 1 & C. 3 & C. 4 & C. 2 & EVA. & C. 3 & C. 3 & C. 3 & C. 4 & C. 2 & C. 3 & $\mathrm{OU}$ & C. 2 & C. 4 & C. 4 & C. 3 & C. 4 & C. 4 \\
\hline & C. 2 & C. 2 & C. 2 & C. 3 & C. 4 & C. 3 & EVA. & C. 4 & C. 3 & C. 4 & C. 4 & C. 2 & C. 4 & IAX & C. 2 & C. 4 & C. 4 & C. 3 & C. 4 & C. 4 \\
\hline & .2 & C. 3 & C. 3 & C. 3 & C. 4 & & & C. 4 & C. 4 & C. 4 & C. 4 & C. 3 & & & & C. 4 & C. 4 & C. 4 & C. 4 & C. 4 \\
\hline OC.FOU & .4 & C. 4 & C. 4 & C. 4 & C. 4 & C. 4 & EVA.ADM & C. 4 & C. 4 & C. 4 & C. 4 & С.3 & C. 4 & REV.CEO & C. 4 & C. 4 & C. 4 & C. 4 & C. 4 & C. 4 \\
\hline
\end{tabular}

\subsection{Consistency of Responses}

Inconsistency occurs when ordinal scales are allocated to subjective preferences of the experts. Thus, it is necessary test what is acceptable. The consistency ratio (CR) compares the consistency index (CI) of the matrix of pairwise comparisons against the consistency 
index of a random-like matrix (RI). The consistency index for criterion weights is calculated as shown in equation (1):

$$
\text { C.I. }=\frac{\lambda_{\max } \cdot(n-1)}{n}
$$

Where $\lambda_{\max }$ is the eigenvalue and $n$ is the number of criteria. The consistency ratio in equation (2) is:

$$
C . R .=\frac{C . I .}{R . I}
$$

The denominator RI is the random index table value according to the number of criteria (Saaty \& Vargas, 2012). The value for a criterion to be judged as consistent must be CR $\leq 0.1$ (Saaty, 1990). For nine criteria, the RI value is 1.45 . We tested the consistency of the experts' pairwise comparisons for them. Table 8 shows that all the participants had CR values lower than 0.1 .

Table 8: Consistency ratios of the experts' preferences related to the criteria.

\begin{tabular}{|cccccc|}
\hline & GM & EE & ME & CE & CO \\
$\lambda_{\max }$ & 9.368 & 9.408 & 9.349 & 9.339 & 9.313 \\
C.I. & 0.046 & 0.051 & 0.044 & 0.042 & 0.039 \\
C.R. & 0.031 & 0.035 & 0.030 & 0.029 & 0.027 \\
\hline
\end{tabular}

\section{Conclusions}

Although we interviewed each member of the plant's staff separately, we were unable to control whether there was any communication between them outside the interview room, so we cannot guarantee there was no suggestion between them regarding the ordering of preferences, possibly introducing bias. Another limitation stems from the tendency that managers may avoid any choice or comment that might suggest a structural problem or operational difficulty with the plant. This type of bias is called prone to bias (Boyce \& Neale 2006) and it is a behavioral problem that is related to the instinct for self-preservation. A process should be followed to allow for minimal bias. Therefore, considering the high degree of education of the respondents, the conduction of the Simos technique followed a straightforward line of reasoning.

To summarize, the Simos and FAHP techniques were used in the proposed method to allow a group of experts to assign weights to the criteria and subcriteria representing the relative importance of a set of operational procedures and safety practices, with the objective of ensuring the availability of the most relevant and updated monitoring and sensing processes to mitigate the dam's vulnerability, often caused by inadequate assessment of its structural conditions. While the Brazilian legislation on dam safety (Brasil, 2010) and the technical guidelines (Eletrobras, 2003; ANA, 2016) are available to assist in specifying the MCDA model, the Simos method to estimate preferences proved to be easier, faster, and more flexible compared with the traditional paired comparison method. Moreover, since it is a ranking procedure, the conversion to the Saaty matrix made it possible to satisfy the transitivity requirement. Regarding the multicriteria method, the fuzzification of the scores attenuated the inaccuracy of the responses, characteristic of the use of subjective numerical scales. The proposed method exploits the experience and opinion of the experts, since they are required to focus on the problem, explain and validate their estimation, and during the same process, weight the degree of importance of each relevant safety procedure. Because they were required to compare the criteria and subcriteria, they are more likely to consider the priorities of the security procedures as proposed by the model and thus determine requirements such as training, accessibility, and specific timelines for updating and detailing.

\section{References}

Adamo N, Al-Ansari N, Laue J, et al. (2017) Risk Management Concepts in Dam Safety Evaluation: Mosul Dam as a Case Study. Journal of Civil Engineering and Architecture 11, p.635-652. https://doi.org/10.17265/1934-7359/2017.07.002

ANA (2016) Manual do Empreendedor sobre Segurança de Barragens, Guia de Orientação e Formulários para Inspeções de Segurança de Barragem II-V-VIIVIII, Brasília: Agência Nacional de Águas.

https://arquivos.ana.gov.br/cadastros/barragens/ManualEmpreendedor/GuiaRevisaoPeriodicaSegurancaBarragem.PDF

Andersen GR, Chouinard LE, Bouvier C, et al. (1999) Ranking Procedure on Maintenance Tasks for Monitoring of Embankment Dams. Journal of Geotechnical and Geoenvironmental Engineering 125, 247. https://doi.org/10.1061/(ASCE)1090-0241(1999)125:4(247)

Arce ME, Saavedra A, Míguez JL, et al. (2015) The use of grey-based methods in multi-criteria decision analysis for the evaluation of sustainable energy systems: a review. Renewable and Sustainable Energy Reviews, 47, 924-932. https://doi.org/10.1016/j.rser.2015.03.010

Arikana R, Dagdevirena M, Kurta M (2013) The Fuzzy Multi-Attribute Decision Making Model for Strategic Risk Assessment, International Journal of Computational Intelligence Systems, 6, 487-502. https://doi.org/10.1080/18756891.2013.781334

Avdi A, Zairi M, Dhia H (2013) Minimization of environmental risk of landfill site using fuzzy logic, analytical hierarchy process, and weighted linear combination methodology in a geographic information system environment, Environmental Earth Sciences, 68, 1375-1389. https://doi.org/10.1007/s12665012-1836-3

Baecher GB. (2016) Uncertainty in dam safety risk analysis. Georisk: Assessment and Management of Risk for Engineered Systems and Geohazards 10, p.92108. https://doi.org/10.1080/17499518.2015.1102293

Boyce C, Neale P (2006) Conducting In-Depth Interviews: A Guide for Designing and Conducting In-Depth Interviews for Evaluation Input, Watertown: Pathfinder. Available at: https://dmeforpeace.org/sites/default/files/Boyce_In\%20Depth\%20Interviews.pdf

Page 8/11 
BRASIL (2010) Lei nº 12.334 de 20 de setembro de 2010. Presidência da República. Brasília: Presidência da República.

http://www.planalto.gov.br/ccivil_03/_Ato2007-2010/2010/Lei/L12334.htm

Chan HK, Wang X (2013) Fuzzy Hierarchical Model for Risk Assessment: Principles, concepts, and practical applications. Springer, London.

Curt C, Talon A, Mauris G. (2008) Using physical measurements, sensory evaluations, and expert judgements in a dam assessment support system. In: 12th IMEKO TC1 \& TC7 Joint Symposium on Man Science \& Measurement, 3 - 5, Annecy: France. Available at :

https://www.researchgate.net/profile/Corinne_Curt/publication/237138869_Using_physical_measurements_sensory_evaluations_and_expert_judgements_in_a

Curt C, Talon A. (2013) Assessment and Control of the Quality of Data Used during Dam Reviews by Using Expert Knowledge and the ELECTRE TRI Method. Journal of Computing in Civil Engineering 27(1). https://doi.org/10.1061/(ASCE)CP.1943-5487.0000187

Donnelly C.R., Acharya A.M. (2020) A Discussion on the Evolution and Application of Quantitative Risk Informed Dam Safety Decision Making. In: Mohd Sidek L., Salih G., Boosroh M. (eds) ICDSME 2019: Water Resources Development and Management. Springer, Singapore

ELETROBRAS (2003) Critérios de Projeto Civil de Usinas Hidrelétricas. Rio de Janeiro: Eletrobrás.

https://eletrobras.com/pt/AreasdeAtuacao/geracao/Manuais\%20para\%20Estudos\%20e\%20Projetos\%20de\%20Gera\%C3\%A7\%C3\%A3o\%20de\%20Energia/Crit

Espino DJ, Hernandez JR, Valeri VCA, Munoz FB. (2014) A fuzzy stochastic multi-criteria model for the selection of urban pervious pavements. Expert Systems with Applications, 41, 6807-6817. https://doi.org/10.1016/j.eswa.2014.05.008

Govindan K, Rajendran S, Sarkis J, et al. (2015) Multi criteria decision making approaches for green supplier evaluation and selection: a literature review. Journal of Cleaner production, 98, 66-83, 2015. https://doi.org/10.1016/j.jclepro.2013.06.046

Hilbert M. (2012) Toward a synthesis of cognitive biases: How noisy information processing can bias human decision making. Psychological Bulletin 138, 211-237. https://doi.org/10.1037/a0025940

ICOLD. (1995) Dam Failures Statistical Analysis, Bulletin 99, International Commission on Large Dams.

ICOLD. (2015) Regulation of Dam Safety: An overview of current practice worldwide. Bulletin Preprint - 167, Paris: International Commission on Large Dams.

Jing M, Jie Y, Shou-yi L et al. (2018) Application of fuzzy analytic hierarchy process in the risk assessment of dangerous small-sized reservoirs. Int. J. Mach. Learn. \& Cyber. 9, 113-123. https://doi.org/10.1007/s13042-015-0363-4

Keprate A, Ratnayake RMC. (2016) Determining the Degree of Fuzziness for Fuzzy-AHP Methodology used for Identifying Fatigue Critical Piping Locations for Inspection, in 20th Jubilee IEEE International Conference on Intelligent Engineering Systems, June 30-July 2.

https://ieeexplore.ieee.org/abstract/document/7555113

Klir GJ, Yuan B (1995) Fuzzy sets and fuzzy logic: Theory and applications. Prentice-Hall, Upper Saddle River.

Koelewijn AR, Bridle R. (2017) Internal erosion in dams and dikes: a comparison. 25th meeting of European Working Group on Internal Erosion in Embankment Dams \& their Foundations, EWG-IE. Available at: http://resolver.tudelft.nl/uuid:0086fdf4-933e-4786-a20b-b5ae93071420

Lewin J, Ballard G, Bowles DS. (2003) Spillway gate reliability in the context of overall dam failure risk. USSD Annual Lecture, Charleston, South Carolina. April 2003. Available at: https://pdfs.semanticscholar.org/4e93/2f4989c4670f1a256280aae93b5583f685b2.pdf?_ga=2.267388750.1942294907.15875874621194159247.1587587462

Li, et al. (2013) AHP Improved Method and Its Application in Identification Risk. Journal of Construction Engineering Management, 139, $312-320$.

https://doi.org/10.1061/(ASCE)C0.1943-7862.0000605

Little RG. (2002) Controlling Cascading Failure: Understanding the Vulnerabilities of Interconnected Infrastructures. Journal of Urban Technology 9, p. 109123. https://doi.org/10.1080/106307302317379855

Masoumi I, Ahangari K, Noorzad A (2018) Integrated fuzzy decision approach for reliability improvement of dam instrumentation and monitoring. Journal of Structural Integrity and Maintenance 3, 114-125. https://doi.org/10.1080/24705314.2018.1461546

Murray A.T., Grubesic T.H. Overview of Reliability and Vulnerability in Critical Infrastructure in Murray A.T., Grubesic T.H. (Editors), Critical Infrastructure: Reliability and Vulnerability, Springer: Verlag Berlin Heidelberg, 2007, ISSN 1430-9602, p.1-8.

Pagano L, Fontanella E, Sica S, et al. (2010) Pore Water Pressure Measurements in the Interpretation of the Hydraulic Behaviour of Two Earth Dams. Soils and Foundations 50, p.295-307. https://doi.org/10.3208/sandf.50.295

Pan Q, Dias D. (2016) The effect of pore water pressure on tunnel face stability. International Journal for Numerical and Analytical Methods in Geomechanics 40, 2123-2136. https://doi.org/10.1002/nag.2528

Papathoma-Köhle M. (2016) Vulnerability curves vs. vulnerability indicators: application of an indicator-based methodology for debris-flow hazards. Natural Hazards and Earth Systems Science 16, 1771-1790. https://doi.org/10.5194/nhess-16-1771-2016

Page $9 / 11$ 
Ribas JR, Arce ME, Sohler FA, Suárez-García A. (2019) Multi-criteria risk assessment: Case study of a large hydroelectric project. Journal of Cleaner Production 227, 237-247. https://doi.org/10.1016/j.jclepro.2019.04.043

Ribas JR, da Silva M (2015) A decision support system for prioritizing investments in an energy efficiency program in favelas in the city of Rio de Janeiro. J. Multi- Criteria Decis. Anal. 22 (1-2), 89-99. https://doi.org/10.1002/mcda.1524

Ribas JR, da Silva M. (2015) A decision support system for prioritizing investments in an energy efficiency program in favelas in the city of Rio de Janeiro. Journal of Multi-Criteria Decision Analysis 22 (1-2), 89-99. https://doi.org/10.1002/mcda.1524

Ribas JR, Pérez-Díaz JI (2019) A multicriteria fuzzy approximate reasoning approach for risk assessment of dam safety. Environ Earth Sci, 78:514. https://doi.org/10.1007/s12665-019-8526-3

Saaty T. (208) Decision making with the analytic hierarchy process. International Journal of Services Sciences 1, 83-98. Available at: https://www.people.iup.edu/rhoch/ClassPages/EnvPlanningSeminar_X/Readings/AHP/Saaty_AHP_2008.pdf

Saaty TL (1990) How to make a decision: The Analytic Hierarchy Process. European Journal of Operational Research, 48, 9-26.

Saaty TL, Vargas LG (2012) How to make a decision: models, methods, concepts \& applications of the Analytic Hierarchy Process. International Series in Operations Research \& Management Science 175, 1-21.

Santillán D, Fraile-Ardanuy J, Toledo MA. (2013) Dam seepage analysis based on artificial neural networks: The hysteresis phenomenon. In: The 2013 International Joint Conference on Neural Networks (IJCNN), Dallas, TX, 2013, pp. 1-8. Available at: http://oa.upm.es/30159/1/INVE_MEM_2013_158308.pdf.

Vojteková J, Vojtek M. (2020) Assessment of landslide susceptibility at a local spatial scale applying the multi-criteria analysis and GIS: a case study from Slovakia. Geomatics, Natural Hazards and Risk 11, 131-148. https://doi.org/10.1080/19475705.2020.1713233

Wijitkosum S, Sriburi T (2019) Fuzzy AHP Integrated with GIS Analyses for Drought Risk Assessment: A Case Study from Upper Phetchaburi River Basin, Thailand. Water 11, 939. https://doi.org/10.3390/w11050939

Yucesan M, Kahraman G (2019) Risk evaluation and prevention in hydropower plant operations: A model based on Pythagorean fuzzy AHP, Energy Policy 126, 343-351. https://doi.org/10.1016/j.enpol.2018.11.039.

Zeng J, An M, Smith NJ (2007) Application of fuzzy decision-making based methodology to construct project risk assessment, International Journal of Project Management, 25, 589-600. https://doi.org/10.1016/j.ijproman.2007.02.006

Zio E. (2016) Challenges in the vulnerability and risk analysis of critical infrastructures. Reliability Engineering \& System Safety $152,137-150$.

https://doi.org/10.1016/j.ress.2016.02.009

Zou Q., et al. (2013) Comprehensive flood risk assessment based on set pair analysis-variable fuzzy model and fuzzy sets AHP. Stochastic Environmental Research and Risk Assessment, 27, 525-546. https://doi.org/10.1007/s00477-012-0598-5

\section{Declarations}

\section{Funding}

The field research received financial support from Corumbá Concessões S/A and Agência Nacional de Energia Elétrica under the R\&D Project PD-02262$0017 / 2019$

\section{Conflicts of interest/Competing interests}

Not applicable.

\section{Availability of data and material (data transparency)}

$\mathrm{R}$ codes are available in Supplementary Information

Code availability (software application or custom code)

Not applicable.

Additional declarations for articles in life science journals that report the results of studies involving humans and/or animals

Not applicable.

\section{Ethics approval}

Not applicable. 
Not applicable.

Consent for publication (include appropriate statements)

Not applicable.

\section{Figures}

\begin{tabular}{|c|c|c|}
\hline $\begin{array}{l}\text { SPECIFICATION } \\
\text { PHASE }\end{array}$ & 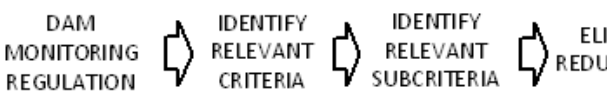 & 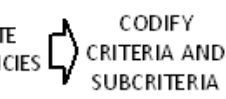 \\
\hline $\begin{array}{l}\text { SCORING } \\
\text { PHASE }\end{array}$ & 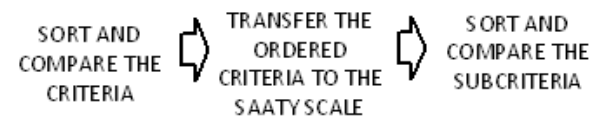 & $\begin{array}{l}\text { TRANSFER THE } \\
\text { ORDERED } \\
\text { SUBCRITERIA TO } \\
\text { THE SAATYS CALE }\end{array}$ \\
\hline $\begin{array}{l}\text { WEIGHTING } \\
\text { PHASE }\end{array}$ & $\begin{array}{c}\text { CALCULATE } \\
\text { DEGREES OF } \\
\text { POSSIBILITY } \\
\text { AND WEIGHTS }\end{array} \Leftrightarrow \begin{array}{c}\begin{array}{c}\text { CALCULATE } \\
\text { THE } \\
\text { IMPORTANCE } \\
\text { DEGREE }\end{array} \\
\begin{array}{c}\text { DETERMINE THE } \\
\text { IMPORTANCE } \\
\text { CLASSES OF THE } \\
\text { SUBCRITERIA }\end{array}\end{array}$ & $\begin{array}{l}\text { AGREGATE } \\
\text { THE } \\
\text { IMPORTANCE } \\
\text { CLASSES }\end{array}$ \\
\hline
\end{tabular}

Figure 1

Flowchart showing the proposed method

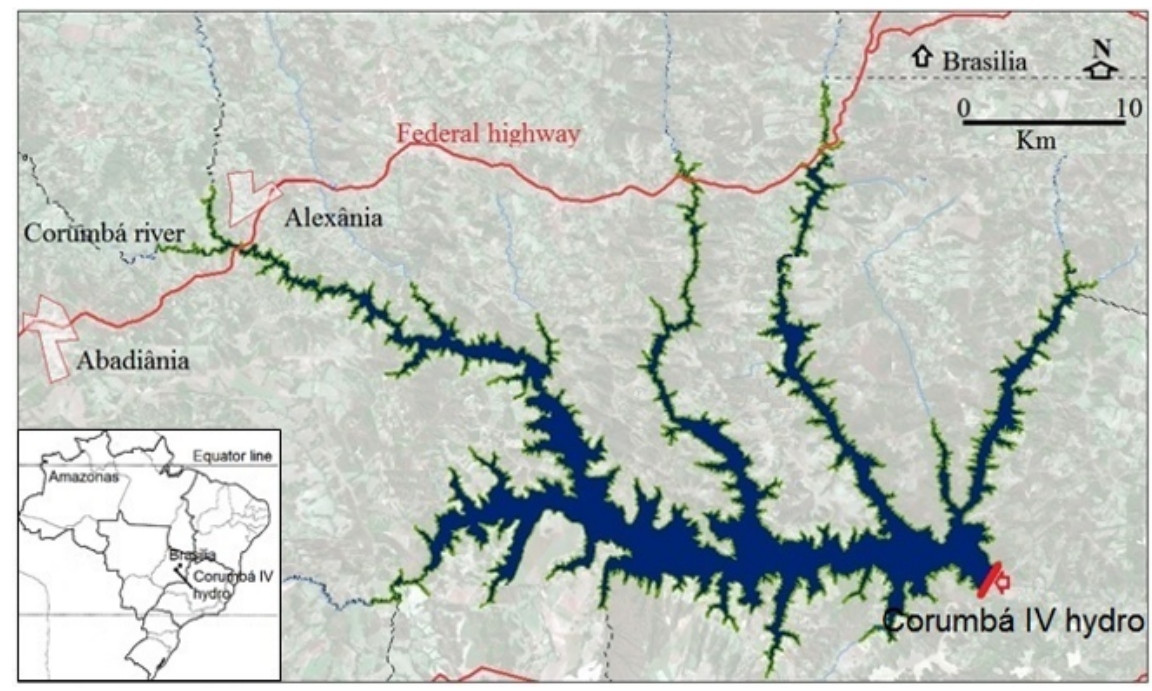

Figure 2

Corumbá IV hydropower plant location 